\title{
The successional change of hollow oaks affects their suitability for an inhabiting beetle, Osmoderma eremita
}

\author{
Thomas Ranius ${ }^{1, *}$, Glenn P. Svensson², Niclas Berg ${ }^{3}$, Mats Niklasson ${ }^{4}$ \& \\ Mattias C. Larsson ${ }^{5}$
}

1) Swedish University of Agricultural Sciences, Dept. of Ecology, P.O. Box 7044, SE-750 07 Uppsala, Sweden (corresponding author's e-mail: thomas.ranius@ekol.slu.se)

2) Lund University, Dept. of Ecology, Sölvegatan 37, SE-223 62 Lund, Sweden

3) Swedish University of Agricultural Sciences, Dept. of Ecology, P.O. Box 7044, SE-750 07 Uppsala, Sweden

4) Swedish University of Agricultural Sciences, Southern Swedish Forest Research Centre, P.O. Box 49, SE-230 53 Alnarp, Sweden

5) Swedish University of Agricultural Sciences, Dept. of Crop Protection Biology, Chemical Ecology, P.O. Box 44, SE-230 53 Alnarp, Sweden

Received 15 Apr. 2008, revised version received 15 July 2008, accepted 23 July 2008

Ranius, T., Svensson, G. P., Berg, N., Niklasson, M. \& Larsson, M. C. 2009: The successional change of hollow oaks affects their suitability for an inhabiting beetle, Osmoderma eremita. - Ann. Zool. Fennici 46: 205-216.

\begin{abstract}
We assessed the presence/absence and population size of a threatened beetle, Osmoderma eremita, inhabiting hollow oaks (Quercus robur). Population sizes varied widely between trees (10\% of the hollow trees hosted two thirds of the individuals), and increased with the volume of wood mould (= loose material of dead wood) and the height of the entrances. Population density (number of adult beetles per litre of wood mould) increased with decreasing growth rate of the trees. Trees with the largest $O$. eremita populations were 300-400 years old. Among hollow trees, the population sizes increased with tree age. This is at least partly due to the fact that the volume of wood mould increased with tree age. Both the size of the largest entrance hole and tree diameter were positively correlated with the estimated wood mould volume, and could thus be used as easily measured proxies for wood mould volume.
\end{abstract}

\section{Introduction}

Old trees provide important habitats for a wide range of invertebrates, epiphytic cryptogams, birds and mammals (Ranius \& Jansson 2000, Kantvilas \& Jarman 2004, Kosinski 2006). Many species are confined to old trees because they are associated with microhabitats that are absent in younger trees and form when the trees age (Warren \& Key 1991, Whitford \& Williams
2002). Tree hollows constitute one of the most significant types of such microhabitats (Ranius \& Jansson 2000, Gibbons \& Lindenmayer 2002). For the associated fauna the quality of the hollow trees is often important. For nesting birds and small mammals, the number of entrances per tree (Gibbons \& Lindenmayer 2002), the size of the entrances (Gibbons et al. 2002, Remm et al. 2006), and distance from the ground (Johnsson et al. 1993, Ruczyński \& Bogdanowicz 2005) 
are critical factors for the suitability of hollow trees. For a species-rich and specialized invertebrate fauna (consisting mainly of beetles, dipterans, and acarids), the presence of wood mould (i.e. loose material of dead wood in tree hollows; Dajoz 2000) is important, and at least some species are absent from hollows where the volume of wood mould is too small (Ranius \& Nilsson 1997, Ranius \& Wilander 2000). Several studies of tree hollows have focused on characteristics of hollows that are important for birds and mammals (e.g. Wormington et al. 2003, Remm et al. 2006), but the volume of wood mould in tree hollows has never been assessed systematically.

Tree hollows change with the ageing of trees (Kelner-Pillault 1974). Because hollow trees are a long-lasting habitat we should expect these changes to be slow, which means that it would take a very long time to understand the dynamics by direct observation of individual trees. An alternative is to compare the characteristics of hollow trees of different age. Knowledge on the dynamics of tree hollows is essential for predicting the future habitat availability for species inhabiting tree hollows.

In this study we used a beetle inhabiting hollow trees, Osmoderma eremita, as a model organism to study the relationships between tree age, other tree characteristics, and the suitability of trees for associated invertebrates. Osmoderma eremita is useful as an indicator species, because the species richness of saproxylic beetles has been found to be higher in hollows and stands of hollow trees where the species is present, in comparison to where the species is absent (Ranius 2002a). Osmoderma eremita occurs still in most European countries, but has suffered from the decline of hollow trees (Ranius et al. 2005). The beetle has been given the highest priority according to the EU's Habitat Directive (Anonymous 1992). For that reason, conservationists across Europe are interested in the monitoring and conservation of this species. Suitable trees are very rare in managed forests, and for this reason most localities are currently situated in old agricultural landscapes (Ranius et al. 2005). We carried out this study in an area in southeast Sweden where the beetle is comparatively frequent and mainly occupies pedunculate oaks (Quercus robur) in pasture land. In earlier studies, presence/absence data and population sizes of the species have been related to easily measured tree characteristics (Ranius \& Nilsson 1997, Ranius 2000, Hedin \& Mellbrand 2003). The main aim of the present study was to put these relationships into a temporal perspective by estimating tree age and analyse how tree characteristics and species occurrence change with tree age. Furthermore, we searched for a variable easy to measure that could be used as a proxy for wood mould volume. This is because the population sizes of $O$. eremita are bigger in trees with large amounts of wood mould (Hedin \& Mellbrand 2003, Ranius 2007), but the amount of wood mould is difficult to measure.

We analysed the presence/absence of adult beetles in relation to characteristics of hollow trees. Presence/absence data were obtained using two methods: pitfall trapping in the tree hollows, and by detecting the male-released sex pheromone in air samples taken from the hollows. Secondly, we analysed the population sizes assessed by capture-recapture in relation to tree characteristics by relating the number of individuals and individual density (number of beetles per litre of wood mould) with different tree characteristics. To understand the successional change of hollow oaks over time, we analysed the relationship between tree age and those tree characteristics that were correlated with the presence of $O$. eremita. Furthermore, we predicted the occupancy of $O$. eremita in different age classes in a hypothetical oak population. This model was based on data from the present study (occurrence of $O$. eremita, and mortality and falling rate of hollow oaks) and other studies. Finally, we tried to identify tree characteristics that could be used as proxies for wood mould volume by correlating wood mould volume with other more easily measured tree characteristics.

\section{Methods}

\section{Study area}

We studied $O$. eremita in an area south from Linköping, southeastern Sweden, with a high 
density of old oaks (e.g. Ranius 2001). In this study we only included trees situated in stands of hollow oaks (i.e. clusters of oaks situated $<250 \mathrm{~m}$ from the closest hollow oak) in which $O$. eremita was captured. Therefore, absences of the species in trees probably reflect low quality of the trees, rather than the absence of dispersal sources (Ranius \& Nilsson 1997, Ranius 2007). Living and dead standing trees of pedunculate oak (Quercus robur) were studied. In 19951997, 24 trees were sampled with pitfall trapping, while in 1998 the study was expanded to 46 trees, then including every tree in which pitfall trapping was possible (the same data set as used by Ranius and Hedin (2001), however with the data of two trees removed because we do not know how the characteristics of these trees have changed since O. eremita was sampled). Usually sampling was possible only in one hollow per tree. In three trees, beetles were captured with two traps, and for those trees the characteristics of the hollow with the largest number of captured beetles were measured.

Due to limited resources, only 23 oaks were air-sampled in 2006. Among these, 10 were sampled using pitfall trapping, while the remaining 13 were studied using air sampling alone. The aim of the pitfall trapping in 2006 was to compare beetle presence/absence with data from air sampling and to get information about when adults were active, so that air sampling was conducted at the right time. The traps were emptied every second day. No population sizes were estimated. The total number of study trees was $59(46+13$ trees), which were situated in the following sublocalities: Hjorthagen, Kalvhagen, Bjärka äng, Bos holme, Storängen, and Brokind. The distance between sublocalities was up to $12 \mathrm{~km}$.

For analysing the correlations between tree age and tree characteristics, we used 126 hollow oaks. These were the oaks in which $O$. eremita was surveyed plus all hollow oaks that were aged in a study of crustose lichens (Ranius et al. 2008). The lichen study was conducted in pastures with a high density of old oaks: Kalvhagen, Bjärka äng, Storängen, Brokind and Sundsbro. Hence, four of these sites were also used in the O. eremita survey, while the fifth (Sundsbro) was situated $6 \mathrm{~km}$ from Bos holme.

\section{Population size estimation}

Adult beetles were captured with pitfall traps set in hollow oaks. The traps were empty jars with the openings leveled with the wood mould surface. To be able to set a trap in a hollow, the entrance hole must be wide enough, $\leq 5 \mathrm{~m}$ from the ground, and the wood-mould surface not too far from the entrance hole. The traps were emptied once a day (for trees studied 1995-1997) or every second day (for trees that were studied for the first time in 1998). Osmoderma eremita was also searched for in the tree hollows and on trunks. Each beetle found was given an individual number by marking on the elytra with an insect needle in a drill. After marking, the beetles were released on the surface of the wood mould and usually the beetles immediately dug down into the wood mould. During 1995 and 1997 the trapping started before the first adults had emerged, while during 1996 and 1998 adults were present at the first day of trapping. Adult beetles occur mainly in the tree hollows and have a maximum life-span of about one month. Trapping ended when the daily total capture fell below one individual, except in 1998, when trapping ended when two captures per day were recorded.

Population sizes were estimated for each tree as the mean value over all years of the study (see Ranius 2001). Craig's (1953) model was used to estimate population sizes from capture-recapture data. Craig's model assumes the captures to be Poisson distributed between individuals. In field data, the distribution is rather close to the Poisson distribution, especially if captures are treated separately for each tree and year (Ranius 2001), which was done in the present study. For trees with less than two recaptures, all captures and recaptures were pooled. The total population size for these trees was estimated from pooled data, and for each tree the population size was assumed to be proportionate with the number of captures in each tree. When the Jolly-Seber method has been used to estimate the total population size of $O$. eremita, no significant difference was obtained in comparison to the estimate by Craig's method (Ranius 2001). The capture rate was too low to allow analysis using the Jolly-Seber method for individual trees. 
Information on beetle presence/absence was obtained from the capture-recapture study (46 trees) and collected by sampling air from the hollows in another 13 trees. The content of $\gamma$-decalactone in the air samples was analysed. This compound has been identified as a sex pheromone released in huge quantities by $O$. eremita males (Larsson et al. 2003). A previous study has shown an $89 \%$ match between the detection of $\gamma$-decalactone and the occurrence of male $O$.eremita within two days from the sampling event, and that samples never contained $\gamma$-decalactone when males were absent (Svensson et al. 2003). We used the odour collection method described by Svensson et al. (2003), with some modifications. In short, a battery-driven pump fitted with a collection filter containing $20 \mathrm{mg}$ Super Q (Supelco) as adsorbent was placed in a hollow. With this equipment, air was usually sampled for 6-7 hours, but sometimes up to 9 hours. Filters were then eluted with $200 \mu 1$ hexane, which was subsequently concentrated to 3-4 $\mu 1$ containing 1 ng $\mu \mathrm{l}^{-1}$ of trans-anethole as internal standard, and the presence/absence of $\gamma$-decalactone in extracts determined using gas chromatography and mass spectrometry (GC-MS). With this method we studied 10 oak trees that were also studied using pitfall trapping, and 13 trees that had too small entrances or a wood mould surface too far from the entrances making pitfall trapping impossible. Hollows up to a height of $6 \mathrm{~m}$ were included. Thus, air sampling made it possible to include trees with characteristics that made them impossible to study with other methods. Air samples were taken on two or three different days, with 1-2 weeks between the occasions. With pitfall trapping in other trees we confirmed that the air sampling was conducted at the time when adult beetles were active.

Previous studies on the habitat requirements of $O$. eremita and other hollow-dwelling beetles have mainly been based on the sampling of adult beetle body parts (Ranius \& Nilsson 1997, Ranius 2002b). The main advantages with the methods used in the current study are that we can quantify the population sizes and ascertain that the beetles are actually present at the time of study.

\section{Measuring tree characteristics}

We estimated the age that the trees had in 2005 using the same method as in Ranius et al. (2008). It was impossible to obtain reliable age estimates for two dead standing trees, hence, they were consequently excluded from analyses related with tree age and tree characteristics. From each tree, two to four increment cores were taken at a height of $0.5-1.3 \mathrm{~m}$. The cores were cross-dated using the classical memory dating method based on conspicuous pointer years (e.g. Stokes \& Smiley 1968). When the pith was reached by any of the increment cores, the age was estimated by counting the annual rings. When the pith was missed, but the best increment core reached a point less than $25 \mathrm{~mm}$ from the pith we estimated distance to the pith by fitting a transparent plastic with imprinted concentric circles on the sample. The number of rings missed was estimated by assuming the growth rate being equal to the three innermost rings of the core. For the remaining trees, age, $a$, was estimated using the following equation:

$$
a=c+r /(k \times g)
$$

where $c$ is the number of annual rings in the longest increment core, $r$ is the radius of the hollow (i.e. distance from the innermost tree ring present to the geometric midpoint), $g$ is the average annual growth rate of the innermost ten years of the increment core, and $k$ is a parameter that depends on how quickly the annual growth rate decreases with tree age. We assumed that the value of $k$ may vary between trees with different characteristics due to different growth patterns.

A function that predicts $k$ was obtained by using tree ring data from 95 trees with intact trunks. From these trees, we simulated hollow trees by assuming the inner part of the trunk to be absent. The absent inner parts corresponded to multiples of ten annual rings. We weighted the data set of simulated trees to obtain the same distribution of trunk diameters and core lengths as among the trees we wanted to age. For each simulated tree, we calculated the true value of $k$ from the intact annual rings. The value of $k$ (or the logarithm of $k$ ) was used as a dependent 
variable in a multiple linear regression model. As independent variables we used characteristics that were available for all trees and might be correlated with the growth rate pattern (trunk diameter, radius of the hollow, growth rate of the inner ten years, and bark crevice depth). By including the independent variables and their logarithms, and successively removing non-significant $(p<0.05)$ variables, we obtained the following function:

$$
k=1.66-0.90 \ln g
$$

where $g$ is the growth rate $\left(\mathrm{mm} \mathrm{yr}^{-1}\right)$ of the inner ten rings of the increment core. There was a strong correlation between the real age and the age estimated with the function $\left(R^{2}=0.839\right)$ for the simulated hollow trees. When Eqs. 1 and 2 were used to estimate tree age, the piths were assumed to be at the geometric centres of the trunks.

Based on the estimated tree age and the radius (without bark), we estimated the mean annual growth rate for every tree. Growth rate might influence $O$. eremita as it has been shown that the decomposition rate of saprotrophic fungi is lower in dead logs of slow-growing trees, and that different fungal species respond differently to the growth rates of trees (Edman et al. 2006). As saproxylic invertebrates are affected by the wood decay of fungi, this fauna may also be affected by tree growth rate, but we are unaware of any study on this.
In 2005-2007, we measured the characteristics of trees and hollows - found to influence occurrence of beetles inhabiting hollow trees (Ranius 2002b) - where the pitfall traps had been set (Table 1). For trees that had obviously changed since the capture-recapture data were collected we used older descriptions, for instance from the survey presented in Ranius (2002b) with data collected in 2000. Because many of the variables were correlated with each other and far from normally distributed, we tested the correlations between the population size of $O$. eremita and tree characteristics using Spearman correlation $\left(r_{\mathrm{s}}\right)$, while for presence/absence data we used the Mann-Whitney $U$-test.

For all 126 trees, we measured the total amount of wood mould in hollows of the trees (however, only entrances $<5 \mathrm{~m}$ from the ground could be included), trunk diameter, and the size and height of all entrances (also entrances $>5 \mathrm{~m}$ from the ground were included). The wood mould volume was measured using two methods. First, it was measured by thrusting a steel ruler as deeply as possible through the wood mould to estimate its depth, and measuring the wood mould surface area. From these estimates, the volume of the wood mould was calculated, assuming it had the shape of an inverted cone. When correlated with $O$. eremita data, the wood mould volume for the hollow with a trap was used, while when correlated with tree characteristics the total wood mould volume for all

Table 1. Characteristics of the pedunculate oaks (Quercus robur) and their tree hollows in the study sites in southeastern Sweden.

Diameter $(\mathrm{cm})$
Shading
Volume of wood mould $(\mathrm{I})$
Size of the entrance hole $\left(\mathrm{cm}^{2}\right)$
Height (m)
Direction of the entrance hole
Aspect
Dead
Tree age (years)
Growth rate $\left(\mathrm{mm} \mathrm{yr}^{-1}\right)$

Diameter $(\mathrm{cm})$

Volume of wood mould (I)

Size of the entrance hole $\left(\mathrm{cm}^{2}\right)$

Height $(m)$

Direction of the entrance hole

Aspect

Tree age (years)
Growth rate $\left(\mathrm{mm} \mathrm{yr}^{-1}\right)$
Trunk diameter $1.3 \mathrm{~m}$ above ground

The vertical projection of foliage around the tree: $<25 \%(0), 25 \%-75 \%(1)$, or $>75 \%(2)$

Volume of loose material in the hollows, estimated by two different methods (see Methods)

Estimated based on the height and width of the entrance, assuming the form of an ellipse

Distance between the ground and the entrance hole

Horizontal (0), angled (1), or upwards (2)

The higher the value, the more sun exposed the aspect: NE (0), N or E (1),

NW or SE (2), W or S (3), SW (4)

Whether the tree is living or dead

Estimated from increment cores and Eqs. 1 and 2

Trunk radius (bark excluded)/estimated tree age 
hollows was used. The increment cores revealed that in many trees the trunk was actually hollow below the depth of the wood mould estimated by the steel ruler. For that reason we also estimated the wood mould volume with a second method, assuming the shape of a cylinder. Then we used the distance from the oldest annual ring in the increment cores to the geometric centre of the trunk as a measure of the radius, and the distance from the ground to the entrance hole as a measure of length. However, for hollows that were situated below the height of the coring, and for trees with cores that reached to the pith, no measure of the wood mould volume was obtained with this method, and for these trees the volume achieved from the first method was used. When correlated with $O$. eremita data, the height of the hollow with a trap was used, while when correlated with tree characteristics the height of the lowest entrance was used as a measure of the cylinder length. The shape of an inverted cone or cylinder is reasonable, because in our study, tree decay is usually initiated from wounds on the trunks (the entrance holes) and spreads out into the heartwood; among 56 old oaks without entrance holes there were never any rotten centres in the increment cores, while among 143 old trees with entrance holes only $25 \%$ produced cores reaching within $20 \mathrm{~mm}$ of the pith (T. Ranius unpubl. data). Wood rot also develops above the entrance holes, but it usually constitutes no habitat for $O$. eremita because no wood mould accumulates there.

\section{Predicting the occurrence of $O$. eremita in a stable oak population}

To put our results into a temporal perspective, we simulated a hypothetical population of oak trees over a period of 500 years, and summarized the trees with and without $O$. eremita that were present at the end of the period. The same kind of data can also be obtained with a snapshot field study. However, such data would be strongly affected by the variation in recruitment and cutting of oaks over time and among sites, while in computer simulations constant conditions could be assumed. We started out with zero oaks and assumed that ten oaks germinated each year.
Trees without hollows were assumed to have a mortality rate according to field data from Lithuanian forests (i.e., 0.3\%/year; Ozolincius et al. 2005), while hollow trees had a higher destruction rate $(0.8 \%)$, based on the data from this study. Thus, we assume that differences in tree mortality between these studies reflect that stability is considerably lower in hollow trunks, at least in those with wide cavities in relation with tree diameter. Our assumption is in line with the increased mortality generally observed among the oldest trees (Monserud \& Sterba 1999), however, we assume that young trees are growing under such conditions that self thinning does not enhance mortality among them. The probability $(P)$ that a tree is hollow was estimated using the following equation: $P /(1-P)=$ $\exp [-9.72+0.028$ Age +1.39 (Growth rate, $\mathrm{mm}$ $\left.\mathrm{yr}^{-1}\right)$, which is based on data from the same area (T. Ranius unpubl. data). We assumed the growth rate to be $1.7 \mathrm{~mm} \mathrm{yr}^{-1}$ because this was the average for oaks in the present study. The frequency of presence of $O$. eremita in hollow trees in each age class (100-year periods) was assumed to be the same as in field data.

\section{Results}

Osmoderma eremita was present in 40 of the 59 trees sampled. In all ten trees that were studied both by air sampling and pitfall trapping, $O$. eremita was present. Among trees only studied by air sampling, there were eleven presences and two absences, which did not differ significantly from trees with pitfall traps situated in the same range of heights (Pearson $\chi^{2}: p=0.348$ ). The presence/absence of $O$. eremita was correlated significantly or close to significance (MannWhitney $U$-test: $p<0.10, n=59$ ) with the following variables: Volume of wood mould ( $p=$ 0.067 , positive correlation), Size of the entrance hole ( $p=0.042$, negative correlation), Height ( $p$ $=0.034$, positive correlation, Fig. 1), and Growth rate ( $p=0.006$, negative correlation).

The annual average number of individuals per tree varied from 0 to 65 . Those $10 \%$ of hollow oaks with the largest populations hosted about two thirds of all individuals. The population size of $O$. eremita was correlated with Volume of 


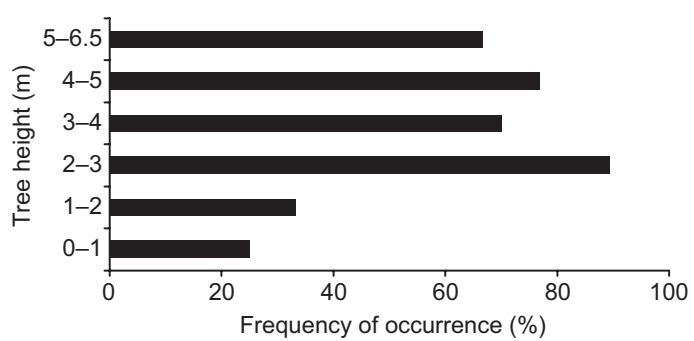

Fig. 1. Frequency of occurrence of $O$. eremita assessed using pitfall trapping and air sampling in relation to the height of the entrance hole. $n(0-1 \mathrm{~m})=8, n(1-2 \mathrm{~m})$ $=6, n(2-3 \mathrm{~m})=19, n(3-4 \mathrm{~m})=10, n(4-5 \mathrm{~m})=13, n$ $(5-6 \mathrm{~m})=3$.

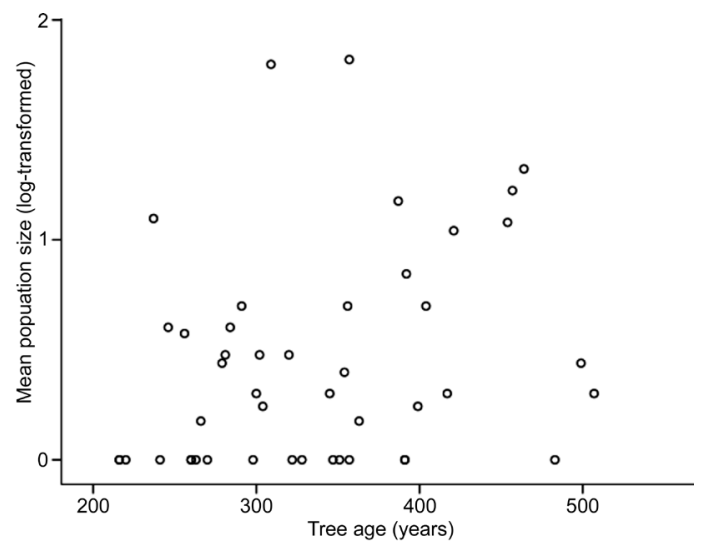

Fig. 3. Population size (estimated number of adult beetles per year 1995-1998, or only 1998) of Osmoderma eremita in relation to estimated tree age. The positive correlation was statistically significant $\left(r_{\mathrm{s}}=0.306, p=\right.$ 0.039).

wood mould (first estimation method: $r_{\mathrm{s}}=0.389$, $p=0.008$, second method: $r_{\mathrm{s}}=0.450, p=0.002$, Fig. 2), Height $\left(r_{\mathrm{s}}=0.294, p=0.047\right)$, Tree age $\left(r_{\mathrm{s}}=0.306, p=0.039\right.$, Fig. 3), and Growth rate $\left(r_{\mathrm{s}}=-0.301, p=0.042\right)$. The population density of $O$. eremita (number of adult beetles per litre of wood mould) was significantly correlated with one variable only: Growth rate $\left(r_{\mathrm{s}}=-0.343\right.$, $p=0.021)$ while its correlation with Height was close to statistical significance $\left(r_{\mathrm{s}}=0.292, p=\right.$ 0.052 ). The $p$ value was not lower than 0.10 for any of the other variables measured.

Hollows were most frequent 2-5 m from the ground, i.e. at levels where the frequency of occurrence of $O$. eremita was high (Fig. 4). In hollow trees, less than 250 years old, hollows were mainly at a height of up to $4 \mathrm{~m}$. Older trees

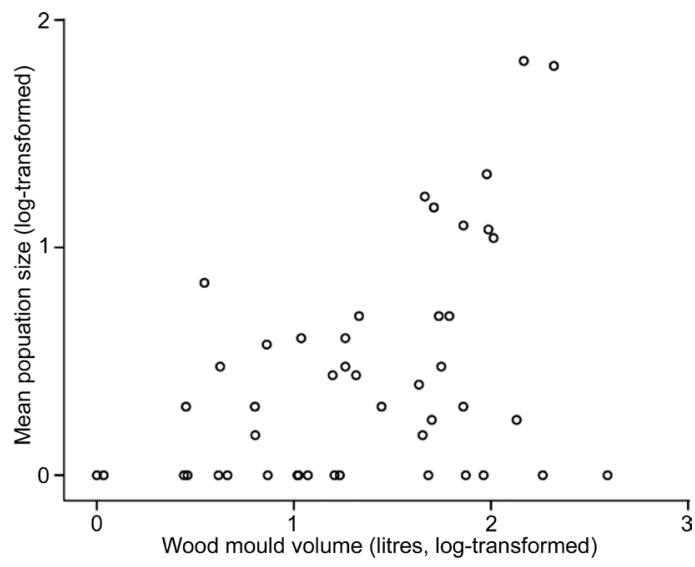

Fig. 2. Population size (estimated number of adult beetles per year 1995-1998 or only 1998) of Osmoderma eremita in relation to wood mould volume. Wood mould volume estimate based on measurements from the entrances. The positive correlation was statistically significant $\left(r_{\mathrm{s}}=0.389, p=0.008\right)$.

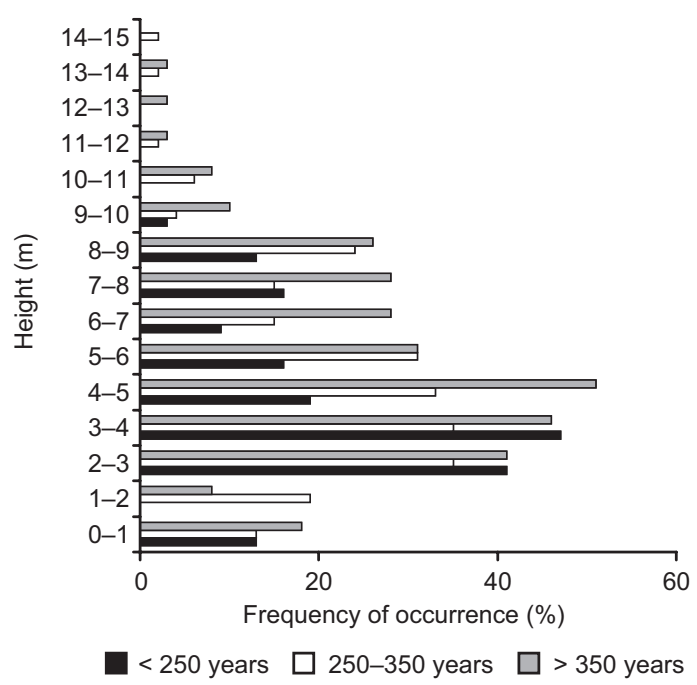

Fig. 4. Frequency of occurrence of entrance holes at different distances from the ground among oaks with at least one entrance hole. $n(<250 \mathrm{yr})=32, n(250-350$ $y r)=54, n(>350)=40$. Data collected in 2005 and 2006 from oaks in southeast Sweden.

had more hollows at higher levels, while the frequency of hollows up to $4 \mathrm{~m}$ was rather similar to the frequency in younger trees (Fig. 4). The area of the largest entrance of the tree increased with tree age $\left(r_{\mathrm{s}}=0.240, p=0.007, n=126\right)$. The volume of wood mould was also positively correlated with tree age $\left(r_{\mathrm{s}}=0.318, p=0.023\right.$, including only trees for which it was possible 


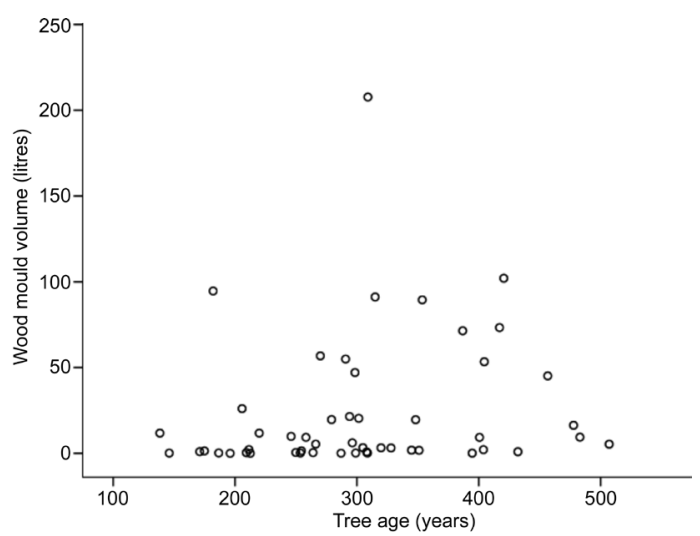

Fig. 5. Estimated wood mould volume in relation to the age of the oaks. Only trees in which sampling was possible in all hollows were included. Wood mould volume estimate based on measurements from the entrances. The positive relationship was statistically significant $\left(r_{\mathrm{s}}\right.$ $=0.286, p=0.042, n=51)$.

to measure wood mould with the first method, in all hollows, $n=51$, Fig. 5). The volume of wood mould (estimated with the first method) was positively correlated especially with the size of the largest entrance, but to some extent also with tree diameter (area of the largest entrance: $r_{\mathrm{s}}$ $=0.714, p<0.001$, tree diameter: $r_{\mathrm{s}}=0.403, p=$ $0.003, n=51$; Fig. 6 ). When the second method for estimation of wood mould volume (using increment cores) was applied, the correlation with the entrance size became weaker, and the correlation with tree diameter stronger (area of the largest entrance: $r_{\mathrm{s}}=0.492, p<0.001$, tree diameter: $\left.r_{\mathrm{s}}=0.653, p<0.001, n=51\right)$. The correlation between the two measures of wood mould volumes was rather strong $\left(r_{\mathrm{s}}=0.626, p<\right.$ $0.001, n=51)$. In 3 of the 126 trees, the amount of wood mould was greater than 300 litres (perhaps much more, because in all of these trees there was at least one hollow in which it was not feasible to measure the amount of wood mould), and they were all between 300-400 years old.

There were 45 living and 3 dead standing trees studied using pitfall trapping during 19951998. In 2007, two of the dead trees remained standing, while one was lying. Six of the 45 living trees had died. Four of these recently dead trees were standing and two lying. This implies that mortality was $1.3 \%$ year, and the falling rate among all standing trees was $0.6 \% /$ year.

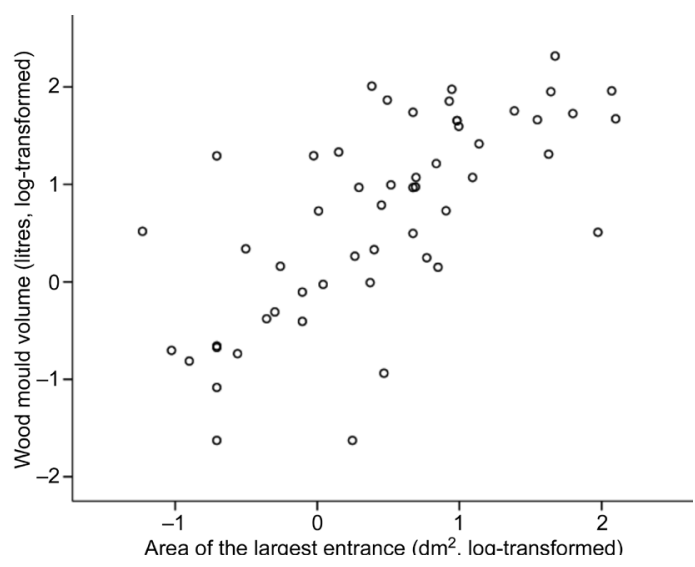

Fig. 6. Relationship between the total volume of wood mould and the area of the largest entrance hole of the oak. Only trees in which sampling was possible in all hollows were included. Wood mould volume estimate based on measurements from the entrances. The positive relationship was statistically significant $\left(r_{\mathrm{s}}=0.724\right.$, $p<0.001, n=51$, tree diameter).

Moreover, one tree was broken, which destroyed the tree hollow even though the tree survived. Thus, the total destruction rate (falling trees + destruction of tree hollows) of the habitat was $0.8 \% / y e a r$. The age of the dying and falling trees did not deviate from the remaining trees (mean age, falling trees: 358 yrs, dying trees: 359 , all trees: $336 \mathrm{yrs}$ ). There was no significant difference in $O$. eremita population size between living and dead standing trees (mean populations size for living trees: $5.4(n=45)$; for dead trees: 3.7 (Mann-Whitney $U$-test: $n=3, p=0.657$ ). Among the four wind felled or destroyed trees, three got their hollows destroyed when falling and in one the O. eremita population decreased after the tree fell; for instance, eight years after falling one individual was observed by the capture-recapture method.

Given the tree mortality and occupancy of $O$. eremita obtained in the present study, and the formation rate of hollows obtained in another study (T. Ranius unpubl. data), we predicted that oaks occupied by $O$. eremita are usually between 200-500 years of age (Fig. 7). At an age of 300-400 years a peak was reached, since the frequency of hollow trees and occupied trees was higher than in younger trees, while occupied trees of a higher age were rarer due to tree mortality. 


\section{Discussion}

This study emphasizes the great variability between individual trees in terms of the size of $O$. eremita populations. This variability could partly be explained by the wide variability in the amount of habitat per tree, i.e. the volume of wood mould. There were no trees that had population sizes much greater than what could be expected from their volume of wood mould. However, there were several trees with $>50$ litres of wood mould but still had no or only very few beetles present (Fig. 2). Thus, wood mould volume reflects the amount of available habitat, but there are other factors that make some trees with large volumes of wood mould unsuitable.

Osmoderma eremita was mainly absent from hollows with entrances close to the ground (Fig. $1)$. This has been shown for several other beetles inhabiting hollow trees, even though for $O$. eremita this pattern has not been statistically significant in previous studies (Ranius 2002b). One possible explanation may be that there are generalist predators (carabid and staphylinid beetles) near the ground that are absent higher up on the trunks. An alternative explanation is that the microclimate changes close to the ground because the wood mould moisture and temperature are affected by the soil, which especially in such trees may be in contact with the wood mould. There was a strong negative correlation between the height and size of the entrance holes $\left(r_{\mathrm{s}}=-0.473, p<0.001, n=59\right)$, which implies that the negative correlation between species' occurrence and size of the entrance hole may be due to the absence of this species from hollows near the ground.

At least in younger hollows, we expected that wood mould would accumulate over time and thus increase in volume with the ageing of the trees. According to our field data, the volume of wood mould did indeed increase with tree age, but with great variability (Fig. 5). One reason for this variability may be that it is difficult to measure the wood mould volumes. Especially for trees with narrow entrance holes and deep, narrow hollows, the amount of wood mould was most likely underestimated. Nevertheless, the fact that many old oaks contained only a few litres of wood mould suggests that in some trees,

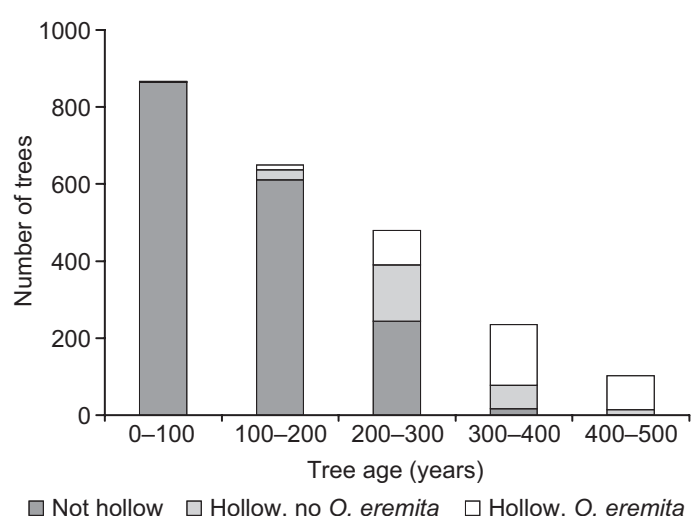

Fig. 7. Predicted number of oaks (Quercus robur) in different age classes, categorised according to whether they have hollows or not, and whether $O$. eremita is present or not. Assumptions: Ten new trees have germinated every year during the last 500 years. The trees become hollow according to a function developed by $\mathrm{T}$. Ranius (unpubl. data) and disappear according to the mortality rate in Ozolincius et al. (2005) and the destruction rate of hollow trees in the present study. For each 100-year period, hollow trees are occupied by 0 . eremita to the same extent as in the present study. If the simulations are conducted over more than 500 years, the category distribution of trees up to 500 years would remain constant; however $>500 \mathrm{yr}$ trees would also be added.

large volumes of wood mould never accumulate, or that the volume may decrease in old trees. This may be because in these trees the decomposition rate of wood mould is sufficiently high to balance the rate of wood mould formation, or wood mould pours out from holes close to the ground. This results in large hollows with small volumes of wood mould. Other old trees may have small volumes of wood mould because the hollows are relatively young. Both of these categories of trees seem to be represented among our study trees.

Both living and dead standing trees are suitable as habitats for O. eremita. However, dead trees constitute a minor part of the hollow trees in our study area, and consequently they are not very important for the overall $O$. eremita populations. Even though we found that $O$. eremita may persist in wind felled trees for some time, observations of $O$. eremita in lying trunks are rare (Ranius et al. 2005). The falling and destruction rate of trees can thus be regarded as the deterioration rate of habitat patches. The observed dete- 
rioration rate of $0.8 \%$ implies that the median life-time of a habitat patch (i.e. hollow tree) would be 87 years. The probability of wind felling among hollow oaks seems to be independent of tree age, which implies a highly variable lifetime among hollow oak trees.

The positive correlation between $O$. eremita population size and tree age (Fig. 3) could be explained by an increase of wood mould volume with the ageing of trees (Fig. 5). Osmoderma eremita is obviously confined to old trees as the formation of hollow commences in oaks at an age of 200-300 years, but this study shows that oaks should be at least 300 years old before they host larger populations of $O$. eremita. Trees that are more than 400 years old are still suitable for the species, however, such trees are relatively few due to tree mortality (Fig. 7).

As measuring wood mould volume is time consuming, more easily measured proxies would be useful. This study shows that a large entrance hole (Fig. 6) and a wide girth of the trees increase the probability that the volume of wood mould is big. The reason for this correlation is that all these variables increase with the ageing of trees. The entrance holes become larger with the ageing of trees, probably because most of the holes are formed by the shedding of branches, and thus reflect the dimension of the branches. On older trees, branches have become wider ( $\mathrm{T}$. Ranius unpubl. data), consequently generating larger entrance holes.

Entrance holes were most common 2-5 m from the ground (Fig. 3), which are levels at which the probability for $O$. eremita presence is high. Osmoderma eremita has been impossible to sample higher up on the trunks (height $>6 \mathrm{~m}$ ), both in this and in other studies in which tree hollows are reached by a ladder (e.g. Ranius $2002 b$ ). Fortunately, only a smaller proportion of the entrance holes are situated at such heights, implying that sampling is feasible for most of the holes. Most likely, many hollows have been formed when old branches have been shed. The oldest branches, which are usually also the largest, occur at the lower parts of a tree. For freestanding trees this is at a height of a few metres, which may explain why entrance holes often are found at these heights (Fig. 3). With tree ageing, branches higher up in the canopy become large enough to generate hollows when shed, which explains why hollows high up are more frequent on the oldest trees. Our study did not indicate any increase in the occurrence of hollows at the ground level with the ageing of trees, even though that has been suggested by Kelner-Pillault (1974). Also hollow-dwelling birds and mammals avoid hollows close to the ground because predation is higher there (Nilsson 1984, Ruczyński \& Bogdanowicz 2005). Therefore, also for these organisms older oaks are probably better than younger hollow trees.

\section{Conclusions for nature conservation}

Oaks with the largest $O$. eremita populations were 300-400 years old. Furthermore, it is trees of that age that are most important as habitat for O. eremita (Fig. 7). This calls for a very long term perspective in the planning for the persistence of invertebrates associated with wood mould. Our study was conducted in oak pastures in Sweden, which is one important habitat for $O$. eremita, and we do not know whether the time scale is the same or different for other tree species, or growing conditions. In parts of Europe, the occurrence of $O$. eremita has been reported from hollow trees assumed to be about 100 years old (Ranius et al. 2005). These trees are mainly poplars, willows and fruit trees but also pollarded trees of pedunculate oak.

In an oak population, hollow trees constitute only a small proportion of all trees (Fig. 7). For a human observer, many hollow trees may seem to be of similar value for the fauna inhabiting hollow trees. However, there is wide variability in the amount of wood mould among hollow trees. Thus, to identify potential localities for $O$. eremita and other threatened invertebrates dependent on wood mould, it is important that this variability is taken into account. To some extent, the trunk diameter and the size of the largest entrance hole of the trees could be used as easily measured proxies; trees with a large girth and larger entrances do, on average, contain more wood mould than those with only smaller entrances. Such measurements are useful to get a rough idea of the amount of wood mould. 
However, because this study showed that the frequency of occurrence of $O$. eremita was negatively correlated with the size of the entrance hole, such measurements generate rather poor information on how suitable a tree is for $O$. eremita. The suitability for $O$. eremita could be measured either by direct estimates of the wood mould volumes, or by assessing the population size of the species.

The largest amounts of wood mould will usually occur in the largest oaks. However, the preference for slowly growing trees shown in this study implies that the best habitat for $O$. eremita is not the largest free-standing oaks situated on fertile soils, but rather we should expect the largest populations to occur in very old trees that are not extremely big, due to a slow or moderate growth rate. This is consistent with the fact that in most studies there has been no significant relationship between the occurrence of $O$. eremita and tree girth (Ranius \& Nilsson 1997, Ranius \& Jansson 2000, Ranius 2002b, however see Ranius 2000), even though there is a positive relationship with the amount of wood mould (Ranius \& Nilsson 1997, Ranius 2000). Entomologists have suggested that many rare saproxylic beetles prefer dead wood from slowly growing trees (e.g. Ehnström 2001), however, the present study is the first scientific evidence for such a relationship.

\section{Acknowledgements}

Keith Alexander gave useful comments on the manuscript. Jonas Hedin contributed with some field data. Erik Göthlin, Andreas Malmqvist, Thomas Persson Vinnersten and Örjan Östman carried out the field work. Support for this study came from the project "Predicting extinction risks for threatened wood-living insects in dynamic landscapes" financed by The Swedish Research Council for Environment, Agricultural Sciences and Spatial Planning (Formas, to TR), Stiftelsen Eklandskapsfonden i Linköpings kommun (to TR, GS, ML), Magnus Bergvalls fond (to ML, GS), Lunds Djurskyddsfond (to GS), and Larsénska fonden (to TR).

\section{References}

Anonymous 1992: Directive 92/43 of the Council of the European Community on the Conservation of habitats and wild fauna and flora. - European Community,
Brussels.

Craig, C. C. 1953: On the utilization of marked specimens in estimating populations of flying insects. - Biometrika 40: $170-176$.

Dajoz, R. 2000: Insects and forests. The role and diversity of insects in the forest environment. - Intercept, London.

Edman, M., Möller, R. \& Ericson, L. 2006: Effects of enhanced tree growth rate on the decay capacities of three saprotrophic wood-fungi. - Forest Ecology and Management 232: 12-18.

Ehnström, B. 2001: Leaving dead wood for insects in boreal forests - suggestions for the future. - Scandinavian Journal of Forest Research, Suppl. 3: 91-98.

Gibbons, P. \& Lindenmayer, D. 2002: Tree hollows and wildlife conservation in Australia. - CSIRO Publishing, Collingwood, Australia.

Gibbons, P., Lindenmayer, D. B., Barry, S. C. \& Tanton, M. T. 2002: Hollow selection by vertebrate fauna in forests of southeastern Australia and implications for forest management. - Biological Conservation 103: 1-12.

Hedin, J. \& Mellbrand, K. 2003: Population size of the threatened beetle Osmoderma eremita in relation to habitat quality. - In: Hedin, J. (Ph.D. thesis), Metapopulation ecology of Osmoderma eremita - dispersal, habitat quality and habitat history. Lund University, Lund.

Johnsson, K., Nilsson, S. G. \& Tjernberg, M. 1993. Characteristics and utilization of old black woodpecker Dryocopus martius holes by hole-nesting species. - Ibis 135 : 410-416.

Kantvilas, G. \& Jarman, S. J. 2004. Lichens and bryophytes on Eucalyptus obliqua in Tasmania: management implications in production forests. - Biological Conservation 117: 359-373.

Kelner-Pillault, S. 1974: Etude écologique du peuplement entomologique des terreaux d'arbres creux (châtaigniers et saules). - Bulletin d'Ecologie 5: 123-156.

Kosinski, Z. 2006: Factors affecting the occurrence of middle spotted and great spotted woodpeckers in deciduous forests - a case study from Poland. - Annales Zoologici Fennici 43: 198-210.

Larsson, M. C., Hedin, J., Svensson, G. P., Tolasch, T. \& Francke, W. 2003: Characteristic odor of Osmoderma eremita identified as a male-released pheromone. Journal of Chemical Ecology 29: 575-587.

Monserud, R. A. \& Sterba, H. 1999: Modeling individual tree mortality for Austrian forest species. - Forest Ecology and Management 113: 109-123.

Nilsson, S. G. 1984: The evolution of nest-site selection among hole-nesting birds: the importance of nest predation and competition. - Ornis Scandinavica 15: 167175.

Ozolincius, R., Miksys, V. \& Stakenas, V. 2005: Growthindependent mortality of Lithuanian forest tree species. - Scandinavian Journal of Forest Research 20 (Suppl. 6): $153-160$.

Ranius, T. 2000: Minimum viable metapopulation size of a beetle, Osmoderma eremita, living in tree hollows. - Animal Conservation 3: 37-43.

Ranius, T. 2001: Constancy and asynchrony of Osmoderma eremita populations in tree hollows. - Oecologia 126 : 
208-215.

Ranius, T. 2002a: Osmoderma eremita as an indicator of species richness of beetles in tree hollows. - Biodiversity and Conservation 11: 931-941.

Ranius, T. 2002b: Influence of stand size and quality of tree hollows on saproxylic beetles in Sweden. - Biological Conservation 11: 931-941.

Ranius, T. 2007: Extinction risks in meatpopulations of a beetle inhabiting hollow trees predicted from time series. - Ecography 30: 716-726.

Ranius, T. \& Hedin, J. 2001: The dispersal rate of a beetle, Osmoderma eremita, living in tree hollows. - Oecologia 126: 363-370.

Ranius, T. \& Jansson, N. 2000: The influence of forest regrowth, original canopy cover and tree size on saproxylic beetles associated with old oaks. - Biological Conservation 95: 85-94.

Ranius, T. \& Nilsson, S. G. 1997: Habitat of Osmoderma eremita Scop. (Coleoptera: Scarabaeidae), a beetle living in hollow trees. - Journal of Insect Conservation 1: 193-204.

Ranius, T. \& Wilander, P. 2000: Occurrence of Larca lata H. J. Hansen (Pseudoscorpionida: Garypidae) and Allochernes wideri C. L. Koch (Pseudoscorpinida: Chernetidae) in tree hollows in relation to habitat quality and density. - Journal of Insect Conservation 4: 23-31.

Ranius, T., Aguado, L. O., Antonsson, K., Audisio, P., Ballerio, A., Carpaneto, G. M., Chobot, K., Gjurašin, B., Hanssen, O., Huijbregts, H., Lakatos, F., Martin, O., Neculiseanu, Z., Nikitsky, N. B., Paill, W., Pirnat, A., Rizun, V., Ruicănescu, A., Stegner, J., Süda, I., Szwałko, P., Tamutis, V., Telnov, D., Tsinkevich, V., Versteirt, V., Vignon, V., Vögeli, M. \& Zach, P. 2005: Osmoderma eremita (Coleoptera, Scarabaeidae, Cetoniinae) in Europe. - Animal Biodiversity and Conservation
28: $1-44$.

Ranius, T., Johansson, P., Berg, N. \& Niklasson, M. 2008: The influence of tree age and microhabitat quality on crustose lichens associated with old oaks. - Journal of Vegetation Science 19: 653-662.

Remm, H., Lõhmus, A. \& Remm, K. 2006: Tree cavities in riverine forests: What determines their occurrence and use by hole-nesting passerines. - Forest Ecology and Management 221: 267-277.

Ruczyński, I. \& Bogdanowicz, W. 2005: Roost cavity selection by Nyctulus noctula and N. leisleri (Vespertilionidae, Chiroptera) in Białowieża primeval forest, eastern Poland. - Journal of Mammalogy 86: 921-930.

Stokes, M. A. \& Smiley, T. L. 1968: An introduction to treering dating. - Univ. of Chicago Press, Chicago.

Svensson, G. P., Larsson, M. C. \& Hedin, J. 2003: Air sampling of its pheromone to monitor the occurrence of Osmoderma eremita, a threatened beetle inhabiting hollow trees. - Journal of Insect Conservation 7: 189-198

Warren, M. S. \& Key, R. S. 1991: Woodlands: past, present and potential for insects. - In: Collins, N. M. \& Thomas, J. A. (eds.), The conservation of insects and their habitats: 155-211. - Academic Press, London.

Whitford K. R. \& Williams M. R. 2002: Hollows in jarrah (Eucalyptus marginata) and marri (Corymbia calophylla) trees. II. Selecting trees to retain for hollow dependent fauna. - Forest Ecology and Management 160: $215-232$

Wormington, K. R., Lamb, D., McCallum, H. I. \& Moloney, D. J. 2003: The characteristics of six species of living hollow-bearing trees and their importance for arboreal marsupials in the dry sclerophyll forests of southeast Queensland, Australia. - Forest Ecology and Management 182: 75-92. 